\title{
The Role of Algerian Universities in National Innovation System (NIS)
}

\author{
Amina Souad Rahali and Abdeslam Bendiabdellah
}

\begin{abstract}
One of the most important functions of universities is to provide a learning environment which releases the latent potentialities of their students and provides them with the abilities they need to promote innovation, in whatever sector of the economy they subsequently work. University research can help support this learning environment and produce outcomes which complement and support business research and innovation.

This paper intends to identify the role of the Algerian universities and research institutions in the National Innovation System (NIS) and investigates the contribution of universities in various manufacturing companies.
\end{abstract}

Index Terms-Innovation, NIS, university, Algeria.

\section{INTRODUCTION}

Universities have long been considered important institutions in national innovation systems (NIS) [1], [2]. Over the decades the university has been delegated a variety of roles in addition to education and research; these include public service, improving national competitiveness, helping to ameliorate social injustice (e.g., affirmative action), and regional economic development. The NIS perspective highlights the fact that countries organize innovation differently. Not unexpectedly, the role of universities in each NIS differs significantly. The NIS perspective has been criticized by scholars who have asserted that innovation processes in industries and regions differ even within the countries. For example, [3] argued that the institutions and entrepreneurship of Silicon Valley and Boston differed appreciably, something she attributed to cultural characteristics, rather than path dependent historical outcomes and different industry foci.

The NIS is important because it sets the basic parameters for what is possible. For example, in China universities can own profit-making firms, while in the United States a university's direct ownership of a commercial firm would invalidate its tax-exempt status - a line that private and public research universities have been unwilling to cross. Thus, national laws and decisions provide the parameters for the actions of organizations such as universities.

The main objective of this paper is to build a theoretical framework linking these universities with the national system of innovation.

Manuscript received February 10, 2014; revised April 10, 2014.

Amina Souad Rahali is with the LARMHO Laboratory, University of Tlemcen Algeria, Algeria (e-mail: souad_rahali@hotmail.fr).

\section{LITERATURE REVIEW}

The concept of innovation systems can be understood as a network of actors/institutions that interact in the production, transfer, diffusion and the use of new knowledge or technology to produce innovation. For [4], a system of innovation includes "all important economic, social, political, organizational, institutional and other factors that influence the development, diffusion and use of innovations". Many scholars [2], [5] agree that - in general - one can group these various organizational, institutional and other innovation actors into three main key categories of actors: Authorities, Suppliers of Knowledge and Skills and The Users/Adopters/Transformers of these knowledge and skills into innovation. In many countries, the position of authorities is often held by the Government, while the suppliers are often represented by Higher Education Institutions and the users are usually Industrial sectors. Scholars argue that the successful innovation performance of the system is determined by the effective interaction between these key actors [6].

The literature broadly defines the NIS as a network of institutions, policies, and agents supporting and sustaining scientific and technical advance [7]-[10]. In knowledge economies, Universities are vital actors in the creation, acquisition, dissemination, and use of knowledge [9].Three core actors to an NIS are Universities, industry, and government [11], [12].

Universities-industry relations are myriad and can include: labor market related linkages, linkages for creation, acquisition, and dissemination of knowledge, and linkages to create new enterprises. Universities are the major educational and training institutions where students and professionals educated and trained gain knowledge and skills, and become part of the labor pool in regional economies [13]. Linkages between Universities and industry also take a variety of forms such as joint $R \& D$ projects, technology licensing, consulting, internships, and other collaborations between firms and Universities to develop a product or technology [14].

In Developing countries, innovation is largely inaccessible, the performance of innovative activities are dismal and where neither market dynamics nor public policy impulses are strong enough to get innovation off the ground.

Unlike NIS of the North, innovation systems in the South cannot be assumed to have similar characteristics [4] and we could not assume the existence ex-ante of NIS: often NISs exist in a preliminary form, are unstructured, disorganized and fragmented, and mostly incomplete, with weak or missing links and weak incentive systems [15], [16]. 
They suffer from a deficit of interactions between the main components [17] and pronounced rent-seeking on the part of the main actors [16] to the extent that they can be considered as nonexistent [18]. The linkages between the various actors are of rather sporadic nature, which leads to more fragmented systems [15]. The institutional infrastructure differs immensely from that of developed countries and is most often characterized by institutional inappropriateness and inadequacy to foster innovative activities and lack of physical and human resources [19]. For example, studies on North and West Africa show the existence of uncoordinated components largely disconnected from public policies [20], [17], [21]. In Algeria, we found that most key players appear to be excluded from the national innovation sphere (foreign firms, professional bodies, independent innovators who constitute incidentally more than $84 \%$ of patents holders).

Only a small group can be considered a being fully included: these are policy-makers, research centers, and research funding agencies [22]. This fragmented and often excluding innovation system feature seems to be quite common in many Developing Countries (Fig. 1).

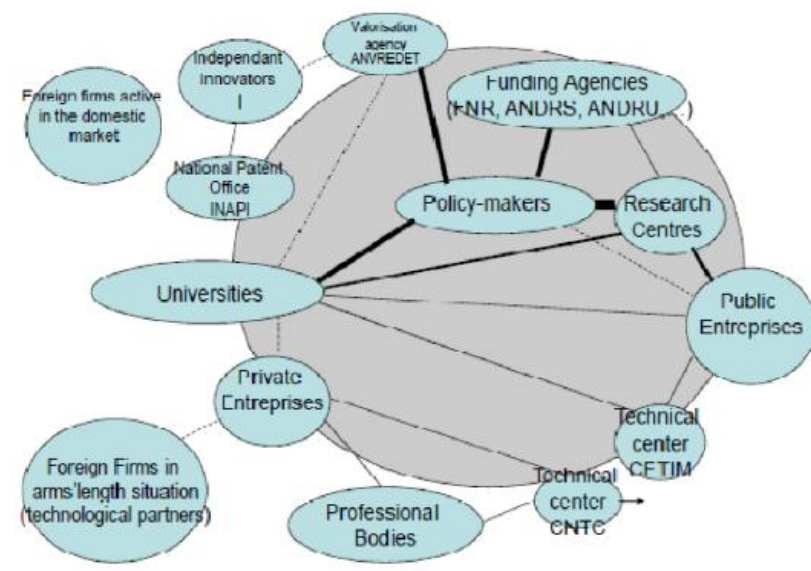

Source: A. Djeflat, P. Devalan, and F. Y. Ettoumi, 'Evaluation des Politiques et Programmes d'innovation dans le secteur industriel', Final Report, European Commission - Ministry of Industry. Brussels: EC, 2007.

Fig. 1. The current national innovation system excludes most key players.

\section{THE ALgERIAN CONTEXT}

The main role of the Algerian universities has essentially been aimed at creating the required capabilities to support the economic development and industrialization of the country through the acquisition of advanced and new technology from developed nations. A series of reforms have been introduced in Algerian higher education Policy.

In 1971, radical changes were introduced such as the increase of the number of student intake and the change on the contents of teaching programs with the aim to enable universities to support the ambitious economic and social government programs [23].

In 1999, a second major reform was introduced with the objective to prepare Algerian universities to support the transition from a centralized to a free market economy [24]. A degree of autonomy was then granted to universities and faculties in order to align part of their activities to the specific needs of their region and industry in order to diversify their sources of funding for research and development programs.
This has stimulated demand from local private and public companies for specialized postgraduate courses and consultancy services which, in turn, has been crucial for the emergence of a fledgling entrepreneurial academic culture. However, this demand has been limited in extent, occasional in character and dependent on isolated actions or instructions from the top (Ministries or National headquarters for state companies).

This second reform did not provide for sufficient power to be devolved to local actors. Algerian universities are still heavily dependent on the Algerian Ministry of Higher Education and Scientific Research of which the main mission of the Algerian universities is around teaching. The level of research activities is rather low and essentially limited to fundamental research of which the themes and objectives are fixed and funded by the State and the Ministry of Higher Education and Scientific Research. The research priorities and management are essentially led by the General Direction of Research and do not always fall within the responsibility of universities.

\section{A. Efforts of $R \& D$ and Patent Diffusion in Algeria}

While the US, the EU and Japan are still leading the world in the term of research and development efforts, they are being increasingly challenged by emerging economies, especially China. (UNESCO Science Report, 2010) The Arab World has been trying to improve its NIS over the last few years, although $95 \%$ of the world researchers are found in Asia, Europe, and North America, whereas Africa, Latin America, Oceania, and Caribbean represent only 5\% of the world researchers (UIS S\&T statistics; 2005) this fact shows a huge gap between the north and south in the matter of research as well as GERD as a percentage of GDP (Algeria is still behind by $0.07 \%$ GERD) (UIS S\&T Database, 2008).

As we all probably know, the innovation system approach was employed using experiences of high income countries, with developed infrastructures and institutions, well built knowledge base, and well-functioning /economic systems, whereas, the situation of developing countries as Algeria is rather different than those of developed economies. It has much lower income levels, a smaller amount of the role played by institutions and infrastructures on $R \& D$ aspects, and less accumulated knowledge. In addition, the foreign direct investments in Algeria are playing much more important role than in the rich industrialised countries applying the national innovation system concept, but it's not the case for the less developed countries. Therefore the relationships between globalisation and national/local systems need to be further researched.

Table I demonstrates some statistics of patents taken from the INAPI offices, and web site, it illustrates the number of Patents delivered for national firms by the INAPI, and the number of patents demanded in the period between 1999 and 2007, we have asked the INAPI offices for recent statistics of this kind, but each time we called they kept saying that it is still confidential and that they cannot offer us such information, because they do not concern the INAPI itself but also the local firms which have asked about the patents of their products and services, as well as the ministry of the industry, anyway; was 214 in the date of 2007, while it was 590 patents in 2006 and 550 in 2005, with the exception of the drop of the number of patents in 2007 , comparing with 
the previous year, patents number was raising by time in the last decade.

TABLE I: STATISTICS OF THE ALGERIAN PATENTS BETWEEN 1999-2007

\begin{tabular}{|c|c|c|c|c|c|c|c|}
\hline \multirow{2}{*}{ yare } & \multirow{2}{*}{ Total of deposits } & \multirow{2}{*}{ certificats } & \multicolumn{2}{|c|}{ Deposits of non residents } & \multirow{2}{*}{ National deposits } & \multirow{2}{*}{ Delivered patents } & \multirow{2}{*}{ Actuel patents } \\
\hline & & & via national way & PCT & & & \\
\hline 1999 & 284 & 06 & 248 & 1 & 36 & 143 & 96 \\
\hline 2000 & 159 & 02 & 127 & 1 & 32 & 78 & 42 \\
\hline 2001 & 147 & 07 & 38 & 56 & 51 & 69 & 61 \\
\hline 2002 & 334 & 04 & 41 & 250 & 43 & 119 & 167 \\
\hline 2003 & 328 & 02 & 16 & 280 & 30 & 250 & 200 \\
\hline 2004 & 393 & 01 & 30 & 304 & 58 & 290 & 322 \\
\hline 2005 & 514 & 01 & 34 & 431 & 59 & 550 & 498 \\
\hline 2006 & 669 & 04 & 47 & 564 & 58 & 590 & 669 \\
\hline 2007 & 852 & 03 & 31 & 734 & 84 & 214 & 852 \\
\hline Total & 5876 & 39 & 2590 & $\begin{array}{c}261 \\
9\end{array}$ & 671 & 2699 & 3553 \\
\hline
\end{tabular}

\section{University-industry Linkages}

The goal of supporting university-industry linkages is to promote the relevance and contribution of universities to socio-economic development. Although there is no step-by-step model describing how university-industry linkages are to be developed. In the National Innovation System (NIS) framework, innovation is viewed as a collective process in which firms do not innovate in isolation but within a larger system involving firms, universities, research centers, government agencies and other actors [25]. The NIS model considers all aspects of the economic and institutional structure of a country that influence the development, diffusion and use of innovations [4].

In the Triple Helix model developed by [26] (Fig. 2), innovation is seen as a product of interaction between three main actors: university, industry and government. In this model, universities focus on establishing institutional interface structures including industry liaison/technology transfer offices, business and technology incubators, and fostering entrepreneurialism through various policies and incentives. Universities, for example, may even look to industry to recruit entrepreneurial researchers to work among their faculty and act as role models.

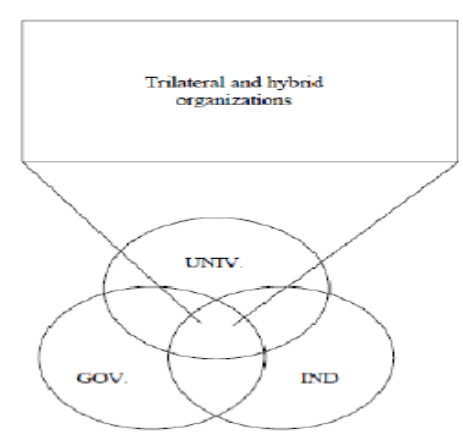

Source: Etzkowitz and Leydesdorff (2000).

Fig. 2. The 'Triple Helix' of University-Industry-Government relations.

The triple helix culture is still at its infancy in Algeria. A greater decentralization devolving more power to local and regional authorities is needed to enable key actors to perform their role in the development of technological capability at regional and national levels. The Algerian case suggests that transfer of knowledge can be expected to be successful when organizations acquire the ability to assimilate and apply this knowledge, and also to manage their relationship with other spheres and institutions in ways that facilitate knowledge production and knowledge sharing [27].

Benefits from university-industry collaboration include: providing alternative funding channels in an era of constrained financing; access to/or acquisition of state-of-the-art equipment; improved curriculum and training in technology-oriented programmes and problem-solving; enhanced employment prospects for students; supplemental income for academic staff; and clearer contribution of universities to the economy, among others (World Economic Forum, 2011; [28]). In the context of fiscal constraints, graduate unemployment, and the need for universities to demonstrate greater accountability to society and respond to national development imperatives, the topic of university-industry linkages is becoming increasingly prominent in the discourse on higher education in Africa.

Although strengthening university-industry linkages offers many potential benefits, enthusiasm should be tampered with realism and recognition of the trade-offs inherent in promoting such linkages. While some universities have prospered significantly through large research contracts and the commercialization of marketable technology, many others have not necessarily accrued substantial revenue through activities directed towards the productive sector, though they have still benefitted in other ways [25].

\section{METHODOlOGY RESEARCH}

This section explains and justifies the research methodology which is essentially qualitative based on 119 case studies. Data about the relationships between universities and the NSI have been collected through in-depth interviews and desk research.

Semi-structured interviews have been conducted in various modes: face-to-face, by telephone with 82 enterprises that have accepted to answer. Average interview length is 16 minutes.

All respondents were directly involved in the innovation strategy or process within their company, they were mainly senior business executive. The sample regroups different sectors: Telecommunications, chemicals, agro-food, textiles, energy industries ...that have been interviewed in the region of Tlemcen and Oued Tlilet in the west of Algeria.

\section{A. Results}

The following figures are the main results of the survey: 
Fig. 3. shows that less than $5 \%$ of the companies interviewed consider universities as a driver of innovation; however a larger portion is attributed to private research institutions.

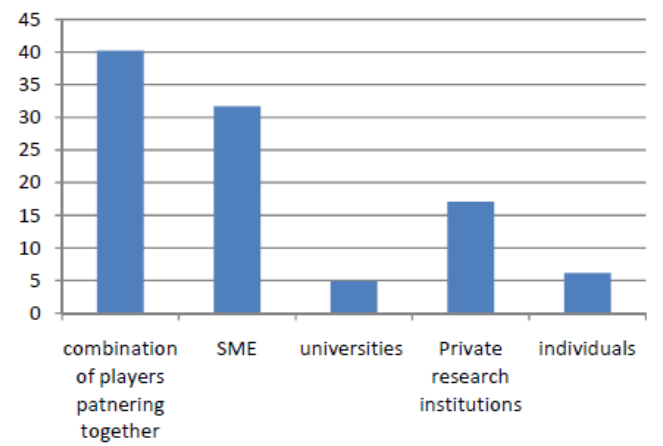

Source: established by the author

Fig. 3. Drivers of innovation.

Combination of players partnering is the main driver of innovation followed by the Small and Medium enterprises then by individuals.

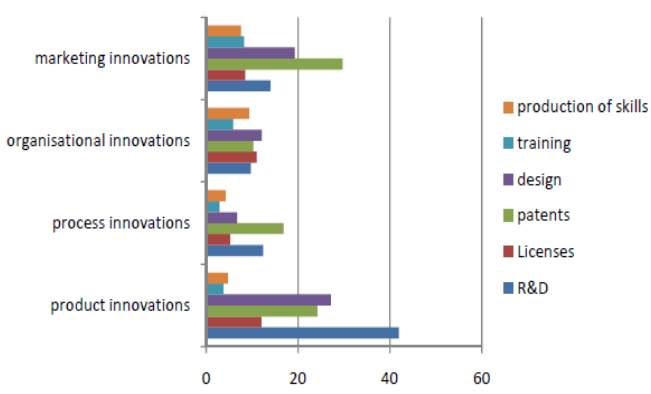

Source: established by the author

Fig. 4. Different universities contributions in innovative firms.

Fig. 4 illustrates four main contributions of universities in innovative actions: R\&D activities, Licenses, patents and designs. These contributions differ from a type of innovation to another. The observations concern the product innovations in which $\mathrm{R} \& \mathrm{D}$ is the main university contribution then about the marketing innovations in which patents play a major role

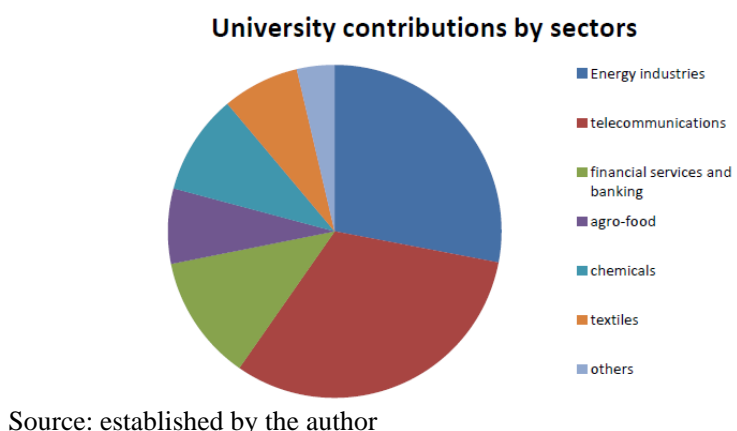

Fig. 5. Sectors in collaboration with universities.

The Fig. 5 shows the industry sectors that benefit most from the contribution of universities it appears that they are mainly telecommunications, energy industries and financial services and banking. The others are partially included.

\section{B. Discussion}

The contribution of universities seems to be negligible in innovation system and firms' respondents recognize fully the need to embrace the changing nature of innovation. They rely mainly on $R \& D$ and scientific research to drive innovation may be more than creativity.

Indeed, the university seems partially included in the innovation system however; companies see little interest in a merger with the university and public research centers.

Research is often seen as the most important driver of innovation, especially of technological innovation. For this reason the measures governments used to assess the performance of universities frequently include indicators of research-related engagement with business, or of the level of patenting, licensing and start ups.

Links between universities and entrepreneurial companies need to be strengthened; also academics and students linkages need to be encouraged to work closely with innovative SMEs.

\section{CONCLUSION}

The role of Algerian Universities is still limited in carrying out R\&D and patents for industry. Universities have an explicit role in the cultural development of Algeria and culture provides one of the important framework conditions within which the innovation system operates. A diverse, open society is not only more creative, it is also more tolerant of difference and more open to the take-up of new ideas and technologies than a more closed society. Indeed, a major factor impacting on innovation success is the preparedness of consumers to take up new things, to take risks and to try ideas. In many cases the exploitation and impact of new technologies depends more on the creativity of consumers than of those who develop the technology. Indeed, universities facilitate an open mind and managed risk taking approach among their skills students and trainings.

Government must give universities the autonomy to operate effectively, and form partnerships. The best people to decide a university's strategy are its own board and faculty heads, not government ministries. Without freedom to operate - with appropriate checks and balances - they cannot form effective partnerships.

Also, help universities strive for excellence. Companies want to work with the best - and so Algeria must take care always to feed and promote its best universities, in order that more job-creating partnerships can be formed. Finally, enhanced survival rate of start-ups that formed partnerships with university researchers.

\section{REFERENCES}

[1] B. A. Lundvall, National Systems of Innovation: Towards a Theory of Innovation and Interactive Learning, London: Pinter, 1992.

[2] R. R. Nelson, National Innovation Systems: A Comparative Study, New York: Oxford University Press.

[3] A. Saxenian, Regional Advantage, Cambridge: Harvard University Press, 1994

[4] C. Edquist, System of Innovation: Technologies, Institutions and Organizations, Oxon: Routledge, 1997.

[5] C. Freeman, "Japan: A new national innovation system?" in G. Dosi, C Freeman, R. R. Nelson, G. Silverberg and L. Soete, Eds., Technology and Economy Theory, London: Pinter, 1988.

[6] D. Archibugi and J. Michie, Technology, Globalization and Economic Performance, Cambridge: Cambridge University Press, 1997.

[7] M. Crow and B. Bozeman, Limited by Design: $R \& D$ Laboratories in the U.S. National Innovation System, New York: Columbia University Press, 1998. 
[8] J. L. Furman, M. E. Porter, and S. Stern, "The determinants of national innovative capacity," Research Policy, vol. 31, pp. 899-933, 2000.

[9] R. R. Nelson and N. Rosenberg, "Technical innovation and national systems," in R. R. Nelson (Ed.), National Innovation Systems: A Comparative Analysis, pp. 3-21, New York: Oxford University Press, 1993.

[10] M. E. Porter and S. Stern, "Innovation: location matters," Sloan Management Review, pp. 28-36, Summer 2001.

[11] H. Etzkowitz, The Second Academic Revolution: MIT and the Rise of Entrepreneurial Science, London: Gordon and Breach, 1999.

[12] D. C. Mowery and N. Rosenberg, "The U.S. national innovation system," in Richard R. Nelson (Ed.), National Innovation Systems: A Comparative Analysis, pp. 29-75, Oxford and New York: Oxford University Press, 1993.

[13] A. Jaffe, The real effects of academic research.American Economic Review, 79(5), 957-970, 1989.

[14] F. Kodama, and L. M. Branscomb, "University research as an engine for growth: how realistic is the vision?" in L. M. Branscomb, F Kodama, and R. Florida (Eds.), Industrializing knowledge: University-industry linkages in Japan and the United States, pp. 3-19, London: MIT Press, 1999.

[15] R. Narula, "Understanding absorptive capacities in an Innovation Systems context: Consequences for Economic and Employment Growth," DRUID Working Paper, no. 04-02, DRUID, Copenhagen Business School, Denmark, 2004.

[16] A. Djeflat, "National Systems of Innovation in the Mena Region," World Bank Institute Report, Washington DC: World Bank, 2004.

[17] V. Casadella, Le Système de Construction de Compétences au Sénégal, Doctoral thesis de doctorat, Université de Perpignan, Perpignan France, 2005.

[18] R. Arocena and J. Sutz, "Understanding underdevelopment today: news perspectives on NSI," First Globelics Conference: Innovation Systems and Development Strategies for the Third Millennium, Rio de Janeiro, Brazil, 2003.

[19] A. Szogs, "Technology transfer and technological capability building in informal firms in Tanzania," Ph.D thesis, CIRCLE, Lund University, Sweden, 2010.

[20] A. Djeflat, "Les Systèmes Nationaux d'Innovation: entre globalisation et territorialisation, in Michel Rautenberg," Dynamiques locales et Mondialisation, Revue CLES, l'Harmattan, Octobre, pp. 131-153, 2003.

[21] H. Carré, "Innovation et développement dans une économie de rente: le cas du secteur agro-alimentaire au Sénégal," in A. Djeflat and B. Boidin eds., Ajustement et Technologie en Afrique, Paris, Publisud.
[22] A. Djeflat, P. Devalan, and F. Youcef Ettoumi, "Evaluation des Politiques et Programmes d'innovation dans le secteur industriel," Final Report, European Commission - Ministry of Industry, Brussels: EC, 2007

[23] M. Bennoune, The Making of Contemporary Algeria, Cambridge University Press, 1988.

[24] A. Benziane, "Economic reforms in Algeria and their impact on higher education and student benefits," Journal of North African Studies, vol. 9 , no. 2, pp. $102-114,2004$

[25] B. Goransson and C. Brundenius, Ed., Universities in Transition: The Changing Role and Challenges for Academic Institutions, New York: Springer, 2011.

[26] H. Etzkowitz and L. Leydesdorff, "The dynamics of innovation: from National systems and mode 2 to a triple Helix of university-industry-government relations," Research Policy, vol. 29 , pp. 109-129, 2000.

[27] M. Saad and G. Zawdie, "From technology transfer to the emergence of a triple helix culture: The experience of Algeria in innovation and technological capability development," Technology Analysis and Strategic Management, vol. 17, no. 1, pp. 1-15, 2005

[28] M. Martin, "Managing university-industry relations: A study of institutional practices from 12 different countries," A Working document in the series, Improving the Managerial Effectiveness of Higher Education Institutions, Paris: International Institute for Educational Planning/UNESCO, 2000.

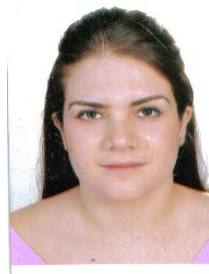

Rahali Amina Souad was born in Tlemcen, Algeria in 1986. She received a magister degree in human resources management from University of Tlemcen (Algeria), in 2010. She has been an assistant professor in Preparatory School of Economics and Commercial Sciences and been involved in several research projects at LARMHO laboratory. Her main area of interest is innovation process in SME's.

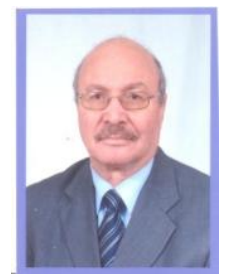

Bendiabdellah Abdeslam was born in Saida, Algeria in 1949. He received $\mathrm{PhD}$ degree from the Louvain University in 1980 .He is currently director of research in Management in LARMHO Laboratory. He was appointed chairman of the board of ethics and professional conduct in University of Tlemcen in Algeria. 